\title{
Winner Take All Politics: How Washington Made the Rich Richer - And Turned Its Back on the Middle Class
}

Jacob Hacker and Paul Pierson

(Simon \& Schuster, 368 pp., \$27.00)

\author{
By Jonathan P. Kelly
}

Books often tell stories. This is true even for works of non-fiction, but it is not often that one finds the non-fiction staking claim to the mysterious detective story. In Winner Take All Politics: How Washington Made the Rich Richer - And Turned Its Back on the Middle Class, political scientists Jacob Hacker and Paul Pierson do just that, telling an engaging, accessible story about the history of inequality in America - the so-called "winner-takeall" economy. The story is one with which most of us are now all-too familiar. CEOs and executives earning $\mathrm{X}$ percent more income than their employees. Hedge fund managers collecting personal incomes of $\$ \mathrm{X}$ millions, much of it untaxed or taxed at only 15 percent, resulting in an effective tax rate that is lower than that paid by middle-class families. Fill in the "Xs" with whatever numbers seem appropriately lurid and exaggerated - you'll likely under-do it. Meanwhile, middle-class wages stagnate. How can this be, especially in the upwardly mobile, egalitarian America of the 21st century? Hacker and Pierson seek to understand this phenomenon, and they theorize that the reasons behind this inequality primarily rest within American politics.

That this inequality exists is one thing. As Henry Paulson - Treasury Secretary under the second President Bush - has said, inequality is an economic fact of life, and it is useless to blame any political party for it (Hacker \& Pierson 2010). Hacker and Pierson's book aims to understand the changing nature of this inequality. Indeed, the authors begin by explicating in painful detail what has happened to inequality over the last thirty years - it has expanded. Quickly. And this growth has continued strongly through the biggest fiscal crisis of several generations, through which average Americans suffered greatly. In 2009, the CEO of Goldman Sachs, Lloyd Blankfein - gleefully oblivious to the parable of the camel through the needle's eye - said he was doing "God's work" (Arlidge 2009). Perhaps he was joking, but this just drew more attention to the fact that the wealthy seem to make more money always, in good times and in bad. We have become inured to this reality, and while there has been no shortage of efforts to explain it there has been a notable lack of concrete answers as to why this is the case.

Addressing this knowledge gap are Pierson and Hacker. As noted, the book is styled as a crime-thriller, a detective story in which they search the political history of the United States for clues that 
might explain why the rich have continued to get richer, even in tumultuous economic times. To that end, they identify two central components of their story. First, they provide the evidence for the growing inequality in America and how it happened. While the economy has grown over the last 30 years, much of that growth has gone to the wealthiest one percent. Those not lucky enough to be in this group have largely lost ground. Next, they explore how American politics has played a central role in fostering the winner-take-all economy. A significant point here is the increasing pressure exerted by the "superrich" on the political class, and how this has further exacerbated the divide between the haves and the have-nots.

The recent history of American inequality - focusing on the work of economists Thomas Piketty and Emmanuel Saez - is one of the strongest sections of the book. It centers on an analysis of tax data that shows how different income groups have fared over the period from 1974 to 2007. This adds evidence to their contention that the American economy has increasingly benefited those already at the top of the heap. It is difficult to find solace in the numbers presented. During this time, the share of income earned by the top one percent of Americans increased from nine percent to 23.5 percent. Stated another way, one percent of Americans controls 23.5 percent of the wealth. The concentration of wealth becomes even denser for the top .01 percent of households; this group controls six percent of national income. The only year in which this figure was higher - and this is so predictable and unimaginative that it cannot help but be true - was 1928, on the eve of the Great Depression. But the hyperconcentration of wealth in 2007 is only part of the story.

More alarming, say Pierson and Hacker, is the sustained growth of hyperconcentration. The Piketty and Saez data show that, starting in 1980, the wealthiest one percent of Americans began to steadily - and rapidly, by historical norms - increase its share of national wealth, with only a few brief reversals occurring over that period. The implications of this steady increase loom right over the horizon. Inequality has expanded through all presidents, all partisan compositions of Congress, and all economic cycles. If none of those factors can arrest this growth, what can? This alone is enough to make one wonder if the curmudgeonly Gore Vidal (2004) had it right after all when he famously pronounced that there is but one political party in the United States, the Property Party, with Democratic and Republican wings.

Finally, the data are examined for signs that the non-rich were made better off during this time, despite being exponentially outpaced by the top one percent. The authors rely on calculations from the Congressional Budget Office (CBO) that are used to identify family income trends. After all, incomes increased over the last 30 years, so it could be that all families were made better off, if not equally so. Yet one knows how this story ends even before reading it. Making assurance doubly sure, the authors report that the top one percent saw its incomes increase by 256 percent during the 1974-2007 time period. The bottom four quintiles saw increases of $11,18,21$, and 32 percent; when divided by 30 years, this doesn't make for a very large annual raise. Furthermore, most of these increases were attributable to an increase in average household work hours, which stemmed from more women working outside the home; without those extra hours, most of the gains for the bottom four quintiles would have been erased.

Many more examples are provided, but by now the picture should be clear. The data are effective and convincing partly because of their sheer weight one cannot help but be awed by the mass of facts, drawn from multiple sources over multiple years, that all seem to point in the same direction. But they are also effective because of the style in which they 
are presented by Hacker and Pierson. The authors submit a relentless parade of figures, depressing data point after depressing data point, earnestly searching all the while for a silver lining that is never there. The urge to slam the book shut or hurl it out a window is strong. Eventually, one accepts this for what it is - a grand guignol of information that leaves the idea of American egalitarianism rent. The evocative power of this approach should not be underestimated.

Upon completing this section of the book, it is easy to conclude that one of the authors' goals has been achieved. As an alert and a wake-up call, as an invitation to pay attention, this book succeeds. After all, how many citizens can one reasonably expect to independently learn all the minutiae involved in the history of US tax policy while remaining conscious? It is a difficult task even for those so inclined, yet this book is highly readable, even when dealing with dry subject matter. But the authors haven't finished yet.

Having laid the foundation for their case - inequality exists in America, and it's getting worse - Hacker and Pierson move on to explaining the causes for the winner-take-all economy. This section of their argument does not convincingly make its case quite as well as the first part of the book. This is not to say that it fails, but the evidence seems more circumstantial than causal. Hacker and Pierson argue that "American politics" is the cause of surging inequality and stagnating wages. As might be expected, the range of topics within "American politics" is vast, and attempting to address all of them is outside the scope of this review. To focus on one of the more important elements, this review will consider the ability of the rich to promote their interests through well-funded and well-organized advocacy groups.

In the authors' view, the massive organization by financial interests is a major cause of the winner-take-all economy. The financial sector has poured more resources into corporate advocacy than any time in the past, with a considerable surge in the number of lobbyists representing Wall Street. In contrast, union membership in the private sector has fallen to seven percent, from nearly 25 percent in the early 1970s. Essentially, the wealthy are better able to employ their resources to pressure politicians into voting for policies that further advantage business interests over "Main Street" interests. This is mostly intuitive and unsurprising, but the specific impacts are telling.

To wit: Hacker and Pierson cite the following daunting statistic. When the affluent support a policy change, it is three times more likely to become law than when they oppose it; when the middle class supports a policy change, the chance of passage is unaffected. Other researchers support this conclusion, describing the bank bail-out of 2008 as an example of how the status quo "amplifies the voices of many corporate actors and virtually shuts out millions of Americans...there is certainly nothing in the interest group system to suggest accurate representation of the views and concerns of all Americans" (Baumgartner 2010, 533). The result is that a few large, well-heeled interest groups can work against the economic interests of most Americans with relatively little opposition.

The weakness with this argument is not the assertion that increasing gains for the rich are related to their unique ability to influence policy; that point is persuasively made. The weakness lies, as Matthew Yglesias (2010) has noted, in the implied connection between middleclass wages and the earnings of the top one percent. Hacker and Pierson do not present data that show an airtight connection. Their data show that non-English speaking countries have not experienced income inequality as dramatically as the United States has; however, these same countries have experienced similar wage stagnation (Cowen 2010). If that is true, then it is possible that the two are not connected as directly as Hacker and Pierson 
imply (Yglesias 2010).

This is not to say that the authors' implication is not or cannot be true; rather, the point is that the connection is not unambiguously borne out by the data that are presented. Ultimately, this is only a minor criticism. It could well be the case that there is a direct economic or political mechanism that connects the earnings of the top one percent to those of the middle class. This book takes an important step in that direction, and it could serve as a call for other political scientists, economists, and social scientists to find the data that would unequivocally suggest such a link. In any event, connected or not, the issues are independently problematic.

Of course, several questions now come to mind. Why does any of this matter anyway, and what can any individual do about it? As you will see below, I believe this book has much relevance and practical value. The other important question is: should I read this book? I strongly believe the answer to that question is "yes." There are a few reasons that come to mind in support of this view, but I think the most important ones are the timeliness of this book and its potential to raise awareness about a vital issue.

The timeliness of this book is exquisite. At the time of writing this review, Congress was in the throes of debating the budget, and will most likely continue to be for the remainder of 2011 and for all of 2012. Much of this debate centered on the Republicans' desire to cut spending for the remainder of the 2011 fiscal year to the tune of $\$ 100$ billion. It is a princely sum, or at least it would be for an individual. For the wealthiest country in the history of the world it is less than a pittance. And when touted as some sort of economic panacea for the long-run fiscal health of the country this sort of thinking sheds any semblance of intellectual honesty and becomes an utter joke.

How does this relate to Winner Take All Politics? The book is a goldmine of the historical progression and nature of inequality in this country. If it were common knowledge - which it most certainly is not - I believe that fewer people would be so adamant about budget cuts that largely impact the 99 percent of society who were not lucky enough to find a golden ticket in their chocolate bar, or those who never received any chocolate in the first place. This is not to imply that fiscal reform can be accomplished by soaking the rich; it cannot. But the authors show that, in the past 30 years, corporations and the wealthiest one percent of Americans used to contribute a much higher percentage of their wealth than they do now and it did not sink the economy. They could afford to do so again. The most common trope trotted out in defense of this policy - trickle-down economics - is a topic that is thoroughly eviscerated by Hacker and Pierson.

Which leads me to the importance of awareness. Raising awareness about the nature of inequality could do much to avert or mitigate the coming interclass strife that I fear this nation is rapidly approaching. The classist society of the United States - which, taboo-status notwithstanding, does in fact exist - hums merrily along in large part because of the ready abundance and availability of "things." Material things. LCD TVs, new cars, smart phones that place the whole bounty of the Information Age at our fingertips 24/7. Not only can we have them, but increasingly we deserve them. All of them can be had at relatively minimal cost. This is significant, as these goods provide feelings of extraordinary comfort and personal freedom. They mollify. Our current age of unprecedented wealth has allowed us, as put by the late, inimitable David Foster Wallace (2009), "all to be lords of our own tiny skull-sized kingdoms". Of course this is a very old idea that stretches back to antiquity. Possibly known to some students of Latin as "bread and circuses," it is the idea of goods as a superficial means of appeasement. Put another way, iPhones and TVs keep the pitchforks dull and shed-bound.

But our modern-day bread-and- 
circuses would, in my view, lose their pacifying properties if it suddenly became less tenable to have all the things that we have gotten used to having. Things have been very comfortable here, at least for the last 60 years or so. It is easy to think this comfort will last forever. But anyone with any sense of history should know that there is no firm and fast law that dictates the perpetual continuation of our comfort. And that makes me wonder what would happen were that comfort to end. How, for example, would this country react to hyperinflation? I am afraid of how that, or another similar crisis, would play out here. We flatter ourselves, at our own peril, if we believe it could never happen to us. Winner Take All Politics provides the information to begin having an adult conversation about how the country can address this burgeoning inequality before another, graver fiscal crisis occurs. It will make people more aware of how this inequality has grown, and perhaps create interest in changing the system that nurtured it. Egalitarian reforms are likely separate from the reforms that will address the country's long-term fiscal health, but if a major crisis does occur I believe our country will handle it better if Hacker and Pierson's advice is heeded.

In Winner Take All Politics, Hacker and Pierson prosecute a powerful argument against the idea of inequality as an inevitable consequence of the modern economy. While the inequality may be inevitable, the magnitude of it certainly is not. Although the book does not present a flawless case against American politics as the culprit in their detective story, the authors comprehensively draw on data that provide strong circumstantial evidence for their position. This brings us to the next step. Their work should be an impetus for other researchers to begin the task of compiling the systematic evidence necessary to show, beyond any doubt, that the culprit they have identified is responsible for the crime. The more data and evidence there is to draw on, the more difficult it will be for entrenched interests to argue for the status quo. Sparking this drive is the first significant contribution of this book.

The second contribution was alluded to earlier. The authors have filled their book with masses of data while not destroying its readability, an accomplishment worth noting. Indeed, rather than being merely tolerable, the book is eminently readable, even with numerous charts, figures, and graphs. This is a great success. The accessibility means that a broad audience can easily understand the nature of the economic disparity in this country and learn about its underlying causes; this can possibly refocus the national dialogue onto the systemic challenges that Hacker and Pierson highlight. This, in my view, is potentially the greatest contribution of their book. A PhD in economics is not required for comprehension. Reading it expanded my knowledge of the issues in an incredibly comprehensive way. I expect that anyone who takes the time to sit down with this book will have the same experience. Do yourself a favor and read it. 


\section{References}

Arlidge, John. 2009. “I’m doing 'God's Work'. Meet Mr. Goldman Sachs.” The Times, November 8. http://www.timesonline.co.uk/tol/news/world/us_and_ameri cas/article6907681.ece.

Baumgartner, Frank R. 2010. "Interest Groups and Agendas." In The Oxford Handbook of American Political Parties and Interest Groups, edited by L. Sandy Maisel and Jeffrey Berry, 519-533. Oxford: Oxford University Press.

Cowen, Tyler. 2010. "Winner-Take-All-Politics: The New Book by Jacob Hacker and Paul Pierson." Marginal Revolution, September 23. http://www.marginalrevolution.com/marginalrevolution/2010/o9/jacob-hacker.html.

Hacker, Jacob S. and Pierson, Paul. 2010. Winner-Take-All-Politics: How Washington Made the Rich Richer - And Turned Its Back on the Middle Class. New York: Simon \& Schuster.

Vidal, Gore. 2004. Imperial America: Reflections on the United States of Amnesia. New York: Nation Books.

Wallace, David Foster. 2009. This Is Water: Some Thoughts, Delivered on a Significant Occasion, about Living a Compassionate Life. New York: Little, Brown and Company.

Yglesias, Matthew. 2010. "Winner Take All Politics." The Matthew Yglesias Blog, September 23. http://yglesias.thinkprogress.org/2010/o9/winner-take-all-poli tics/.

Jonathan P. Kelly is a second year Master of Public Policy student at The George Washington University, with a concentration in public budget and finance. He holds a BA from Duquesne University in Pittsburgh, PA. He most recently interned at the Government Accountability Office. He spends much time reading budget news to see if said office will be able to offer him a job. His other free time is generally spent playing volleyball. 